13

\title{
Жидкометаллический полевой источник электронов на основе пористого GaP
}

\author{
(C) С.А. Масалов, ${ }^{1}$ Е.О. Попов, ${ }_{1}^{1}$ А.Г. Колосько, ${ }^{1}$ С.В. Филиппов, ${ }^{1}$ В.П. Улин, ${ }^{1}$ В.П. Евтихиев, ${ }^{1}$ А.В. Атращенко ${ }^{2}$ \\ ${ }^{1}$ Физико-технический институт им. А.Ф. Иофрфе РАН, \\ 194021 Санкт-Петербург, Россия \\ ${ }^{2}$ Университет ИТМО, \\ 197101 Санкт-Петербург, Россия \\ e-mail: sergeym@mail.com
}

(Поступило в Редакцию 16 февраля 2017 г.)

Представлен новый способ создания жидкометаллического полевого эмиттера. Обработка пористого кристалла бинарного полупроводникового соединения GaP импульсами высокого напряжения в вакууме позволила получить на его поверхности устойчивые структуры в виде дискретных кластеров галлия. Данные структуры показали хорошие эмиссионные свойства: стабильные токи на уровне нескольких микроампер, а также достаточно высокую равномерность распределения эмиссионных наноцентров по поверхности.

DOI: 10.21883/JTF.2017.09.44921.2210

\section{Введение}

Одной из задач современной эмиссионной электроники является создание сильноточных стабильных источников электронов, способных функционировать в техническом вакууме. Такие источники востребованы в генераторах СВЧ колебаний, генераторах рентгеновского излучения, в лазерах на свободных электронах, в системах накачки полупроводниковых лазеров, в ускорителях заряженных частиц, в опытных установках управляемого термоядерного синтеза, а также в системах ионных ракетных двигателей [1,2].

Основным видом импульсных сильноточных источников являются взрывоэмиссионные катоды, работающие в режиме коротких и сверхкоротких импульсов $[3,4]$. Основным их недостатком на сегодняшний день являются нестабильность токовых характеристик и недолговечность.

Стандартным видом неимпульсных источников электронов является термокатод. Однако нагрев термокатода требует больших энергозатрат и дополнительных конструкторских решений.

Более выгодными в плане эргономичности и долговечности являются холодные полевые катоды на основе микро- и наноструктур с многоострийной эмиссионной поверхностью. В перспективе они способны заменить как термокатоды, так и взрывоэмиссионные катоды.

Существует ряд литературных обзоров, посвященных возможностям этого класса эмиттеров [5-8]. Плотности эмиссионных токов, получаемые с этих источников, существенно превышают плотности токов, достигаемые на термокатодах. Однако нестабильность, связанная с возникновением взрывных процессов и необратимой деградацией поверхности, не позволяет внедрить их в массовое производство.

Впервые значимые величины полевого эмиссионного тока были получены на многоострийных катодах, созданных Спиндтом [9]. С помощью техники фотолитографии ему удалось создать упорядоченный массив молибденовых микроострий, который обеспечивал полный ток до $2 \mathrm{~mA}$.

Использование кристаллических нитевидных наноструктур (CuO, $\mathrm{ZnO}, \mathrm{MgO}$ и т.д.) также дает возможность получать эмиссионные токи. Однако получение высоких токов ограничено термической деградацией эмиттера $[10-12]$.

C точки зрения требований к качеству вакуума, самыми перспективными видами эмиттеров являются эмиттеры на основе углеродных наноструктур, которые демонстрируют токи на порядок выше других видов эмиттеров (десятки миллиампер) $[13,14]$.

Наиболее доступными в изготовлении являются нанокомпозиты, созданные на основе неориентированных углеродных структур. Их основным недостатком является сильный разброс геометрических параметров наноострий, который приводит к неоднородному распределению плотности эмиссионного тока по поверхности. Однако по сравнению с ориентированными наноуглеродными структурами они обладают существенно большей стойкостью к вакуумным разрядам и соответственно большей долговечностью [15].

Высокие уровни эмиссионных токов и хорошую стабильность в условиях технического вакуума демонстрируют полевые эмиттеры на основе жидкометаллических структур. Основным их достоинством является обратимость формы, так что в случае возникновения взрывных процессов исключается необратимый переход к заниженным эмиссионным характеристикам [16].

Однако создание многоострийных жидкометаллических структур весьма проблематично [17-20]. В работах $[18,19]$ для создания выступов на поверхности слоя жидкого галлия, необходимых для возникновения полевой эмиссии, применялось непрерывное механическое воздействие (звуковые волны). Кроме конструкторской сложности, данная система в принципе не допускает произвольной ориентации в пространстве, требуя 
именно горизонтального расположения эмиссионного жидкого слоя.

Еще одним способом создания жидкометаллических эмиттеров является применение пористой структуры тонкой пленки полиэтилентерефталата, обработанной по технологии трековых мембран. Отверстия в мембране заполняются жидким галлием, что дает набор обособленных микроострий [20]. Однако из-за высокой стоимости данная технология не получила широкого применения. К тому же при возникновении вакуумных разрядов полимерная пленка, формирующая эмиссионные центры, постепенно разрушается.

Используя особые свойства пористого полупроводникового материала $\mathrm{GaP}$, нам удалось создать стабильный многоострийный жидкометаллический полевой эмиттер.

\section{Установка для исследования эмиссионных свойств катодов}

Подробное описание используемой экспериментальной установки и методики изучения эмиссионных свойств полевых катодов можно найти в [21].

Методика основана на подаче высокого напряжения на полевой эмиттер в планарной геометрии расположения электродов на расстоянии $300 \mu \mathrm{m}$. Диаметр медного анода составлял $5 \mathrm{~mm}$. Уровень вакуума в измерительной камере не хуже $10^{-7}$ Torr.

Сканирование высоким напряжением производится в двух режимах (рис. 1): „медленном“ (уровень постоянного напряжения плавно меняется с помощью компьютеризированного блока питания FID Technology) и „быстром“ (полусинусоидальными импульсами частотой $50 \mathrm{~Hz})$.

Установка оснащена системой визуализации распределения эмиссионных центров по поверхности образца. Захват изображения осуществляется с помощью длиннофокусного USB микроскопа.

Многоканальный сбор, запись и онлайн-обработка эмиссионных данных производятся с помощью программы, написанной на LabView 2013.

Получение масс-спектрометрических данных основано на использовании времяпролетного масс-спектрометра отражательного типа собственной конструкции.

\section{Технология создания матрицы пористого GaP}

Рассмотрим первый этап создания эмиттера - получение пористого GaP. Известно, что при особых режимах электрохимического травления кристаллических полупроводников в них возникает множество пор, диаметр которых зависит от свойств исходного кристалла, состава электролита, плотности тока травления и температуры [22].

Исходным материалом являлись пластины сильнолегированного $n$-GaP с концентрацией носителей $3.7 \cdot 10^{18} \mathrm{~cm}^{-3}$ и толщиной $280 \mu \mathrm{m}$.
Перед электрохимической обработкой для удаления слоя, нарушенного механической полировкой, проводилось травление пластин в горячем растворе $\mathrm{Br}_{2}$ в изобутиловом спирте.

Электрохимическое травление производилось в $2.5 \mathrm{M}$ водном растворе $\mathrm{KOH} \mathrm{с} \mathrm{использованием} \mathrm{потенциоста-}$ тического режима при напряжении $8 \mathrm{~V}$ в течение $4 \mathrm{~min}$. Использование пластин с ориентацией (111)Р обеспечивало образование в кристалле вертикальных нанопор, которые отделял от поверхности переходный слой (толщиной $\sim 2.5 \mu \mathrm{m})$, не обладающий преимущественной ориентацией направления распространения пор.

Для удаления из нанопор летучих продуктов электрохимических реакций полученные образцы промывались в деионизованной воде и отжигались в высоком вакууме (не ниже $10^{-5} \mathrm{~Pa}$ ) в течение $40 \mathrm{~min}$ при температуpe $500^{\circ} \mathrm{C}$.

Для удаления переходного слоя и открытия нанопор с вертикальной ориентацией образцы были обработаны методом ионного травления в аргоне.

Морфология поверхности и структура изготовленных таким образом пористых матриц $\mathrm{GaP}$ были изучены с помощью сканирующего электронного микроскопа JEOL JSM-7001F (Япония). Результаты измерений показали следующие параметры: глубина пор $40 \mu \mathrm{m}$, диаметр пор 25-30 nm, расстояние между порами (шаг решетки) $50-60 \mathrm{~nm}$.

Таким образом, полученный образец состоял из сплошного слоя $n$-GaP и химически модифицированного пористого слоя $\mathrm{GaP}$ толщиной $\sim 40 \mu \mathrm{m}$.

\section{Технология создания полевого эмиттера}

Для создания эмиссионных структур на поверхности пористого $\mathrm{GaP}$ была произведена его контролируемая обработка высоковольтными электрическими разрядами непосредственно в измерительной установке, описанной выше. При этом сплошной слой $n-\mathrm{GaP}$ являлся проводящим электродом, который был связан с основной измерительной цепью омическим контактом.

На рис. 2, $a$ представлены временны́е зависимости амплитудных значений эмиссионного тока и напряжения, зарегистрированные в ходе обработки в быстром режиме сканирования (с усреднением сигналов в интервале $1 \mathrm{~s}$ ). Отметим, что серия вакуумных разрядов фиксировалась не только в виде электрических сигналов, но и в виде световых вспышек, наблюдавшихся через подключенный к измерительной камере длиннофокусный микроскоп.

После нескольких таких воздействий эмиссионные характеристики образца стабилизировались и вакуумные разряды при токах $\sim 1 \mathrm{~mA}$ перестали возникать (рис. 2, $b$ ).

Исследование образца с помощью сканирующего электронного микроскопа показало, что высоковольтная обработка привела к радикальному изменению структуры поверхности пористого GaP. Изображения SEM этой 


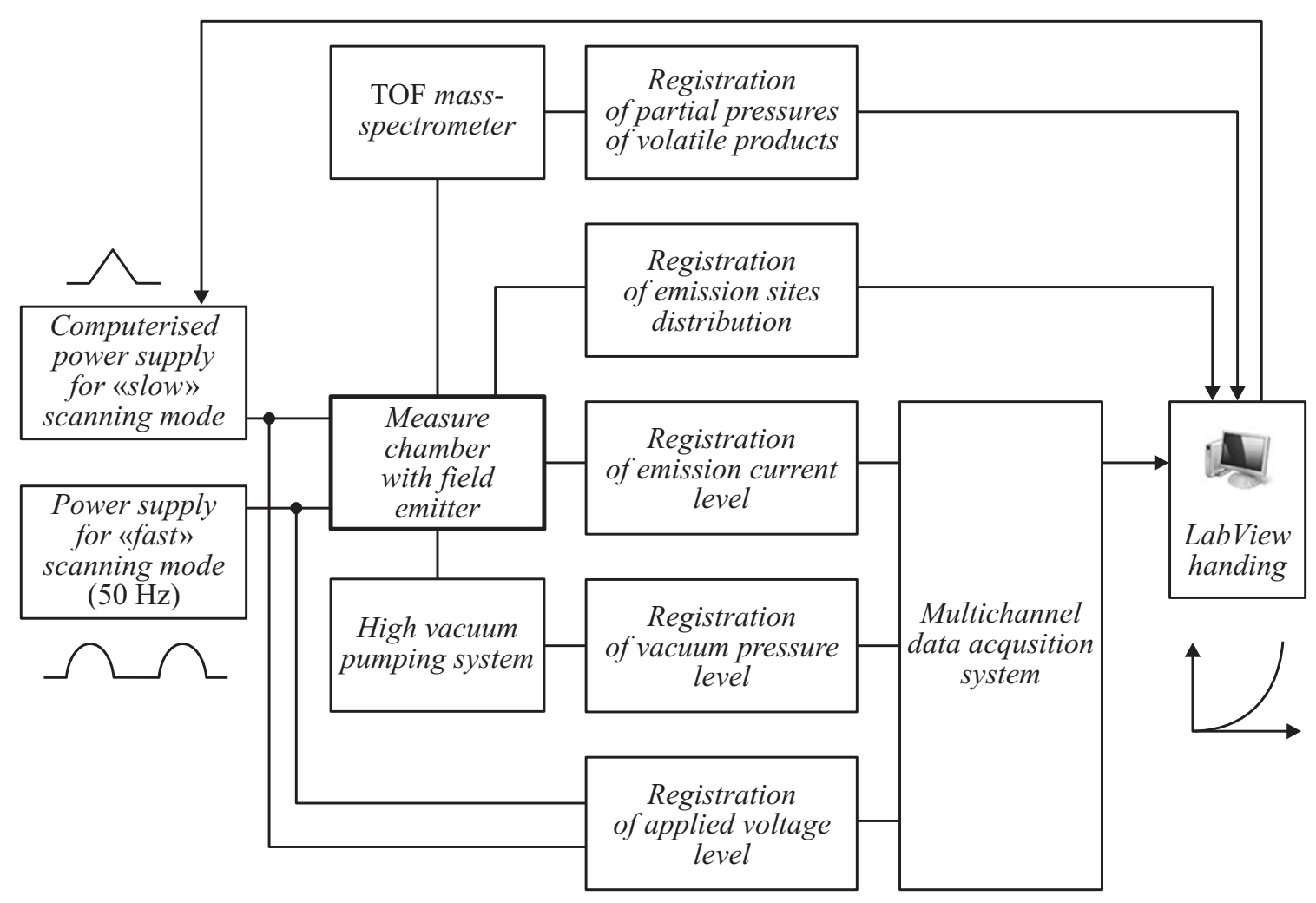

Рис. 1. Блок схема многоканальной регистрации эмиссионных данных.
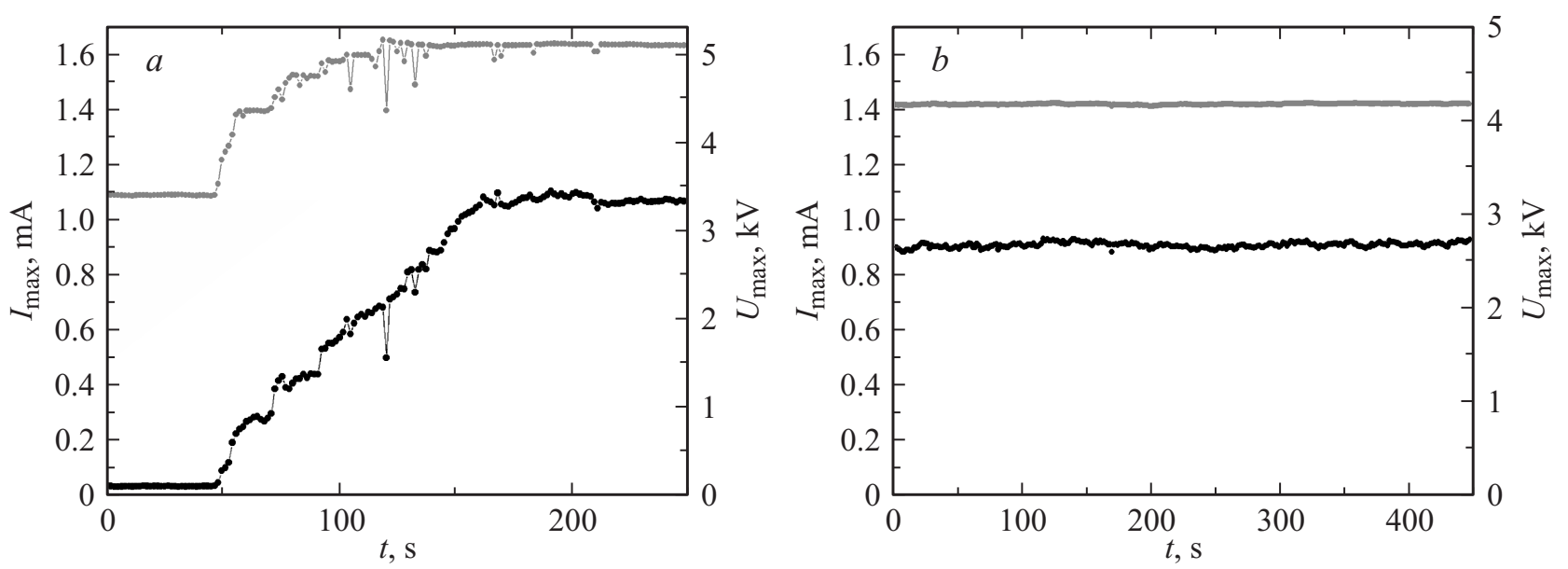

Рис. 2. Выведение образца на рабочий режим: ход тренировки образца $(a)$, амплитудные значения тока и напряжения; временная стабильность сигналов в рабочем режиме $(b)$.

поверхности в разных масштабах и на разных стадиях процесса приведены на рис. 3.

Аналогичные изображения были получены в известных работах Г.А. Месяца для различных материалов эмиттера [23]. Им было показано, что возникающие в процессе электронной эмиссии разряды сопровождаются локальными взрывами на поверхности катода. В основе этих взрывов лежит лавинная эмиссия электронов из локальных областей катода (так называемые эктоны), которая приводит к быстрому разогреву материала и заканчивается выбросом вещества в межэлектродное пространство с образованием плазменной дуги. Время жизни эктона порядка нескольких наносекунд. За это время он испускает мощный токовый импульс. В результате эктонного взрыва на поверхности катода образуются кратеры, которые мы и наблюдаем на поверхности нанопористого образца после серии вакуумных разрядов (рис. 3, b).

Температура в области локального выброса достаточно велика и, поскольку в нашем случае используется бинарное полупроводниковое соединение $\mathrm{GaP}$, происходит его разложение на компоненты. При этом атомарный 

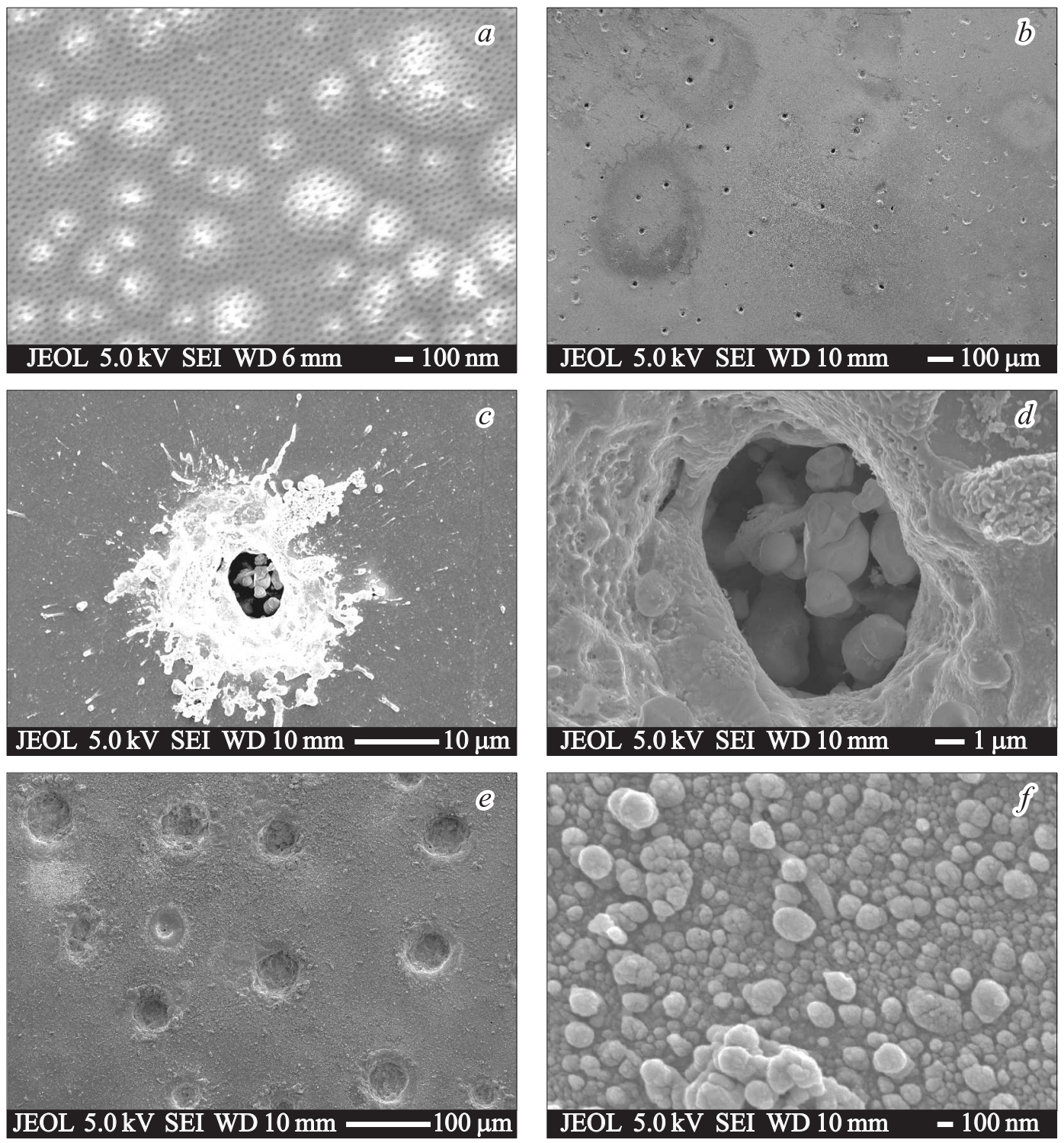

Рис. 3. SEM-изображения поверхности образца: $a-$ исходная нанопористая структура GaP; $b-$ результат обработки вакуумными разрядами - множество кратеров на поверхности; $c$ - один из кратеров - след от электрического разряда; $d-$ кратер с кристаллитами $\mathrm{Ga}$ внутри; $e$ - кратеры на поверхности образца, возникшие в результате продолжительной обработки; $f-$ кристаллиты Ga на поверхности образца между кратерами.

фосфор, имеющий наименьшую температуру испарения, уходит из материала катода, оставляя в токоведущем канале жидкий галлий, который затем разбрызгивается взрывом в пространство вокруг кратера (рис. $3, c)$. Эту модель подтверждает тот факт, что галлиевые кристаллиты наблюдаются не только на поверхности образца, но и в глубине образованных взрывами кратеров (рис. $3, d$ ).

Многочисленные выбросы приводят к покрытию поверхности образца вокруг кратеров микро- и наноразмерными частицами галлия (рис. $3, e, f$ ).

Испарение фосфора с поверхности образца подтверждают масс-спектроскопические данные, полученные в процессе вакуумных разрядов (рис. 4).

Отметим, что возникающее при вакуумном разряде газодинамическое ускорение ионов катода приводит к массопереносу катодного материала на анод, так что после обработки образца анод также оказывается покрыт галлием. Более того, вакуумный разряд приводит и к обратному массопереносу: материал анода испаряется и попадает на катод. Спектры XPS показали появление небольшого количества меди в структуре образца.

Проанализируем причины возникновения эмиссионного тока в исходной пористой структуре $\mathrm{GaP}$.

В работе [24] проводилось исследование электрофизических свойств поверхности исходного пористого образца с использованием сверхвысоковакуумного туннельного микроскопа (LS SPM фирмы OMICRON). Опыты показали, что пористый слой $\mathrm{GaP}$ практически не имеет свободных носителей, а в области пор на поверхностных состояниях сосредоточен значительный отрицательный 

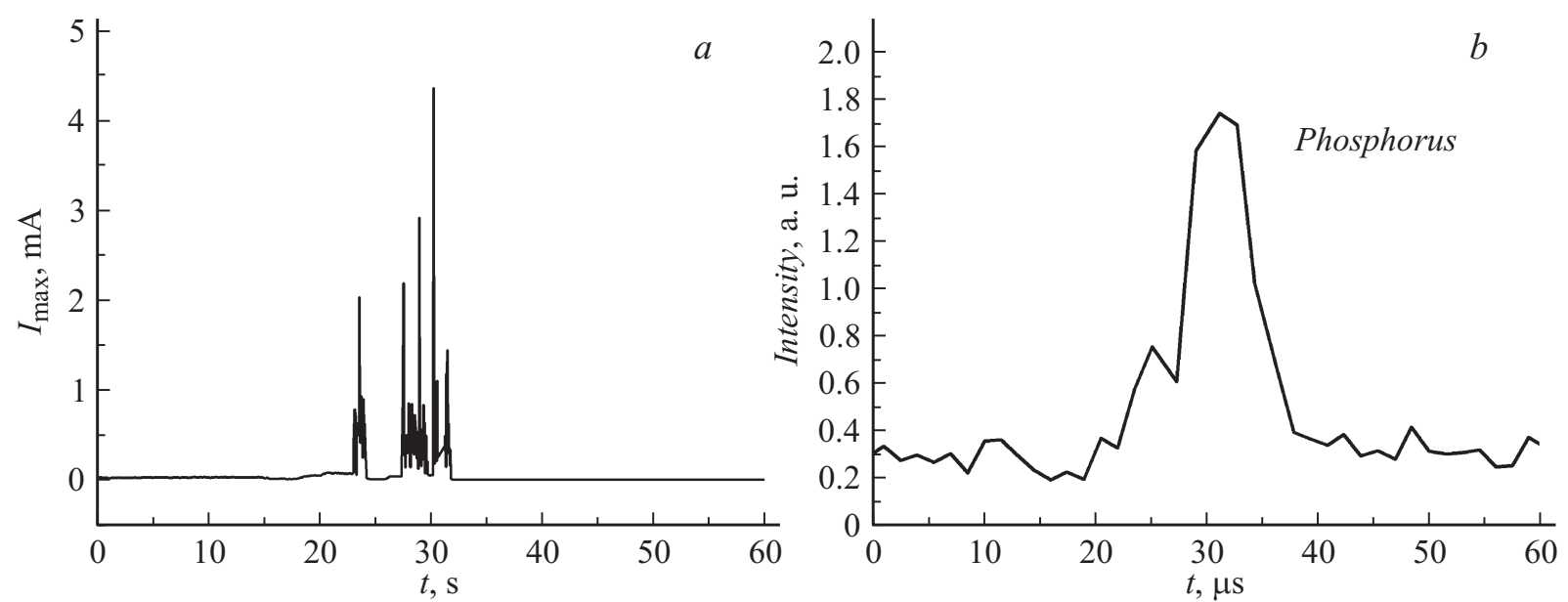

Рис. 4. Временнб́е зависимости уровня эмиссионного тока $(a)$ и парциального давления фосфора в межэлектродном пространстве $(b)$, сопровождающие вспышку вакуумного разряда в ходе обработки образца.

заряд. Видимо, именно этот локализованный заряд играет ключевую роль в возникновении электрических токов через образец, так как в аналогичном материале $n$-GaP, лишенном нанопор, полевой эмиссии при тех же уровнях напряжения не наблюдалось.

Возможным механизмом протекания тока по нанопорам является термополевая эмиссия электронов из локализованных центров захвата - эффект Пула-Френкеля, который описывается следующей зависимостью плотности эмиссионного тока от величины приложенного поля и температуры материала:

$$
J(F, T)=e N_{c} \mu F \exp \left(-\frac{e \Psi}{k T}\right) \exp \left(-\frac{\beta F^{1 / 2}}{k T}\right) .
$$

Здесь $J(F, T)$ - плотность эмиссионного тока, $F-$ внешнее электрическое поле, $T$ - температура, $e-$ заряд электрона, $k$ - постоянная Больцмана, $\beta=$ $=\sqrt{\frac{e^{3}}{4 \pi \varepsilon \varepsilon_{0}}}-$ постоянная Пула-Френкеля, $N_{C}-$ эффективная плотность состояний в зоне проводимости пористого $\mathrm{GaP}, \mu$ - подвижность электронов, $e \Psi-$ потенциальный барьер центра захвата [25].

По формуле (1) была проведена оценка плотности тока (в программе Mathcad) с учетом внешнего приложенного поля и поля, возникающего из-за большого отрицательного заряда на поверхности пор. Согласно исследованиям работы [24], возможной причиной образования такого заряда является наличие нанокластеров $\mathrm{Ga}_{2} \mathrm{O}_{3}, \mathrm{GaP}$ и ассоциированных с ними поверхностных состояний акцепторного типа. Расчеты показали возможность протекания тока, способного вызвать значительный локальный разогрев пористой структуры.

\section{Эмиссионные свойства образца}

Рассмотрим эмиссионные характеристики полученного нами полевого эмиттера. Известно, что частицы галлия обладают свойством менять свою форму в сильных электрических полях, образуя острийные микрокатоды [20]. В нашем случае это означает, что после обработки поверхности образца пористого $\mathrm{GaP}$ вакуумными разрядами основной вклад в полевую эмиссию дают образовавшиеся на его поверхности капли галлия.

Эмиттеры этого класса обладают высокой стабильностью, которая обеспечивается взаимосвязью силы поверхностного натяжения жидкометаллического острия с внешним электрическим полем. Для оценки радиуса формирующихся острий можно использовать следующее соотношение, которое связывает радиус вершины микрокапли $r_{0}$ и внешнее поле $F[26]$ :

$$
\frac{\varepsilon_{0} F^{2}}{2}=\frac{2 \sigma}{r_{0}}
$$

где $\varepsilon_{0}=8.85 \cdot 10^{-12} \mathrm{~F} \cdot \mathrm{m}^{-1}$ - электрическая постоянная, $\sigma=0.712 \mathrm{~N} \cdot \mathrm{m}^{-1}-$ коэффициент поверхностного натяжения галлия. Расчеты показали, что при используемых в работе напряженностях поля и разумных значениях плотности тока величина $r_{0}$ находится в пределах 20-40 nm.

Согласно нашим представлениям, высокая стабильность полученного эмиттера также обусловлена разделением токовой нагрузки по большому числу таких эмиссионных центров, распределенных по поверхности образца случайным образом.

Для визуализации распределения эмиссионных центров нами был использован компьютеризированный автоэмиссионный проектор. Обработка картины, полученной при уровне эмиссионного тока $100 \mu \mathrm{A}$, позволила построить статистику макроцентров (самых ярких точек, светящихся пятен на картине) и определить вклад $(I \cdot N)$ в полный эмиссионный ток групп макроцентров, имеющих одинаковую геометрию, т.е. одинаковый уровень яркости $Y$ на картине распределения (рис. 5, $a$ ). Макроцентры считались, начиная с уровня яркости $Y_{0}=160$ (всего 256 градаций) для исключения шумовой засветки. 

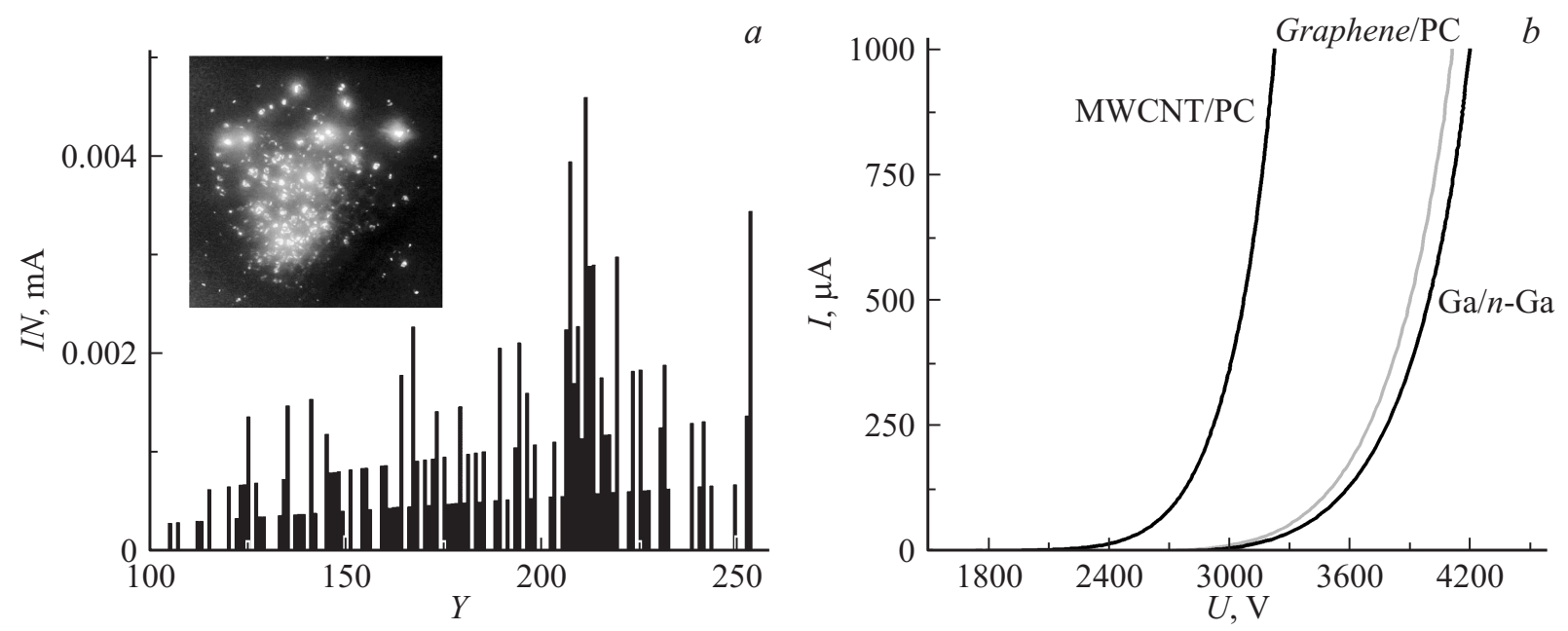

Рис. 5. Характеристики образца $\mathrm{Ga} / n-\mathrm{GaP}: a-$ зависимость токового вклада макроцентров от их уровня яркости; $b-$ сравнение BAX образца с характеристиками нанокомпозитных эмиттеров MWCNT/PC и Graphene/PC.

Яркость каждого макроцентра $Y$ считалась пропорциональной его эмиссионному току $I$.

В случае равномерного распределения макроцентров по яркостям гистограмма должна была иметь линейный рост. Тенденция такого роста наблюдается и на экспериментальной зависимости, однако при уровне яркости $Y=210$ наблюдается особенность, которая указывает на наличие наиболее часто встречающегося радиуса эмиссионных центров. Однако токовый вклад этой группы центров не является определяющим для общего эмиссионного тока.

На рис. 5, $b$ представлено сравнение ВАХ полученного эмиттера $(\mathrm{Ga} / n-\mathrm{GaP})$ и эмиттеров на основе наноуглеродных композитов: углеродные нанотрубки в полистироле (MWCNT/PC), графен в полистироле (Graphene/PC). Уровень порогового напряжения для эмиттера на основе галлия оказался близок к пороговому напряжению эмиттера на основе графена, при этом жидкометаллический галлиевый эмиттер демонстрирует высокую стабильность и долговечность в работе.

\section{Заключение}

Разработан метод создания многоострийного жидкометаллического эмиттера из нанопористого кристалла GaP. Изучены образующиеся в результате на поверхности кристалла структуры. Показано, что рабочими элементами полученного эмиттера являются дискретные кластеры галлия, образовавшиеся при диссоциации $\mathrm{GaP}$ в результате серии вакуумных разрядов. Мы полагаем, что туннельные токи, необходимые для развития взрывной эмиссии и возникновения вакуумного разряда, протекают по стенкам нанопор и обусловлены эффектом Пула-Френкеля. Проведен анализ равномерности распределения токовой нагрузки по эмиссионным центрам на поверхности образца. Проведено сравнение зарегистрированной ВАХ образца с BAX других наноструктурированных полевых эмиттеров. Эмиссионные характеристики жидкометаллического эмиттера оказались близки к характеристикам эмиттера на основе графена.

\section{Список литературы}

[1] Месяи, Г.А. Генерирование мощных наносекундных импульсов. М.: Сов. радио, 1974. 256 с.

[2] Литвинов Е.А. // СОЖ. 1998. Вып. 6. С. 100-105.

[3] Литвинов Е.А., Месяи, Г.А., Проскуровский Д.И. // УФН. 1983. Т. 139. Вып. 2. С. 265-302.

[4] Рухадзе А.А., Богданкевич Л.С., Росинский С.Е., Рухлин В.Г. Физика сильноточных релятивистских электронных пучков. М.: Ленард URSS, 2016. 192 с.

[5] Parmee R.J., Collins C.M., Milne W.I., Cole M.T. // Nano Convergence. 2014. N 1. P. 1-34.

[6] Соминский Г.Г., Тумарева Т.А. // Известия вузов. Прикладная нелинейная динамика. 2009. Т. 17. Вып. 3. С. 17-54.

[7] Фурсей Г.Н. Автоэлектронная эмиссия. СПб.: Лань, 2012. $320 \mathrm{c}$.

[8] Evtukh A., Hartnagel H., Yilmazoglu O., Mimura H., Pavlidis D. Vacuum Nanoelectronic Devices: Novel Electron Sources and Applications. Chichester. John Wiley \& Sons, 2015. 464 p.

[9] Spindt C.A., Brodie I., Humphrey L., Westerberg E.R. // J. Appl. Phys. 1976 Vol. 47. N 12. P. 5248-5263.

[10] Zhan R.Z., Chen J., Deng S.Z., Xu N.S. // J. Vac. Sci. Technol. 2010. Vol. 28. P. 558-561.

[11] Chen D., Song X., Zhang Z., Li Z., She J., Deng S., Xu N., Chen J. // Appl. Phys. Lett. 2015. P. 243105-1-5.

[12] Ma L.A., Lin Z.X., Lin J.Y., Zhang Y.A., Hu L.Q., Guo T.L. // Physica E. 2009. Vol 41. P. 1500-1503.

[13] Saito Y. Carbon Nanotube and Related Field Emitters. Weinheim: Wiley-VCH, 2010. 504 p.

[14] Елецкий А.В. // УФН. 2010. Т. 180. № 9. С. 897-930.

[15] Machida H., Honda S., Fujii S., Himuro K., Kawai H., Ishida K., Oura K., Katayama M. // Jpn. J. Appl. Phys. 2007. Vol. 46. N 2. P. 867-869.

[16] Fursey G.N., Shirochin L.A., Baskin L.M. // J. Vac. Sci. Technol. 1997. Vol. 15. P. 410-421. 
[17] Mitterauer J. // Appl. Surf. Sci. 1995. Vol. 87/88. P. 79-90.

[18] A.c. № 342242. Автоэмиссионный жидкостный катод. А.Д. Лебедев, Г.Н. Фурсей, И.Ю. Барташюс, Л.И. Праневичус. Автореф. канд. дис. 1972. Б.И. № 19.

[19] Широчин Л.А. Жидкая проводящая поверхность в сильных электрических полях и взрывные эмиссионные процессы. СПб., 2004. 302 с.

[20] Коровин О.П., Попов Е.О., Шредник В.Н., Каратеикий С.С. // Письма в ЖТФ. 1999. Т. 25. Вып. 8. С. 39- 44.

[21] Попов Е.О., Колосько А.Г., Филиппов С.В., Романов П.А., Федичкин И.Л. // Наноматериалы и наноструктурыXXI век. 2016. Вып. 1. С. 14-26.

[22] Улин В.П., Конников С.Г. // ФТП. 2007. Т. 41. Вып. 7. C. $854-866$

[23] Месяи Г.А. Эктоны в вакуумном разряде: пробой, искра, дуга. Ч. 1. М.: Наука, 2000. 184 с.

[24] Масалов С.А., Атращенко А.В., Улин В.П., Попов Е.О., Колосько А.Г, Филиппов С.В. // Письма в ЖТФ. 2016. Т. 42. Вып. 22. C. 39- 48.

[25] Kundu T.K., Joseph Ya-Min Lee // Ferroelectrics. 2005. Vol. 328. P. 53-58.

[26] Григорьев А.И., Ширяева С.О. // ЖТФ. 1987. Т. 57. Вып. 9. C. 1706-1713. 